\title{
Fluoretação do sal para consumo humano - Uma possibilidade
}

\section{Fluoridation of salt for human consumption - A possibility}

DOI: $10.46919 / \operatorname{archv} 2 \mathrm{n} 8-002$

Recebimento dos originais: 01/11/2021

Aceitação para publicação: 20/12/2021

\author{
Adelcio Machado dos Santos \\ Doutor em Engenharia e Gestão do Conhecimento (UFSC). \\ Pós-Doutor em Gestão do Conhecimento (UFSC).
}

Docente, pesquisador e orientador do Programa de Pós-graduação em Educação da Universidade Alto

Vale do Rio do Peixe (UNIARP).

Rua Victor Baptista Adami, 800 - Centro, Caçador, Santa Catarina, Brasil. CEP 89500-199.

E-mail: adelciomachado@gmail.com

\author{
Ricardo Klauberg \\ Especialista em Administração \\ Gestão Pública e Políticas Sociais. \\ Cirurgião Dentista. Bacharel em Odontologia (UFSC). \\ E-mail:ricardoklauberg@gmail.com
}

\section{RESUMO}

Estudo com objetivo de identificar como a fluoretação do sal para o consumo humano, pode contribuir na saúde da cavidade bucal. Trata-se de um estudo qualitativo, exploratório, de revisão bibliográfica sistemática. Os resultados apontam a preocupação no mundo, em relação à doença da cárie dentária, a partir da primeira metade do século XX. Inúmeros países da Europa e da América Latina adicionam fluoretos ao sal de cozinha consumido pela população, para prevenção da doença. O Brasil optou na década de 1970, pela fluoretação da água pública, mostrando-se indiferente a realidade geográfica do território nacional. Outro aspecto, que chama atenção, é o descumprimento formal de alguns estados no cumprimento da legislação. Conclui-se que o Estado Brasileiro enfrenta uma crise de legitimidade causada por inúmeros problemas sociais, como pobreza e desemprego, refletindo inclusive na área da saúde bucal.

Palavras-Chave: Fluoretação, Sal, Saúde Bucal.

\begin{abstract}
Study aimed to identify how salt fluoridation for human consumption can contribute to the health of the oral cavity. This is a qualitative, exploratory, systematic literature review study. The results point out the concern in the world, regarding the dental caries disease, as from the first half of the 20th century. Several countries in Europe and Latin America add fluorides to the cooking salt consumed by the population, to prevent the disease. Brazil opted in the 1970s for the fluoridation of public water, showing indifference to the geographic reality of the national territory. Another aspect that calls attention is the formal noncompliance of some states with the legislation. It is concluded that the Brazilian State faces a legitimacy crisis caused by numerous social problems, such as poverty and unemployment, reflecting also in the area of oral health.
\end{abstract}

Keywords: Fluoridation, Salt, Oral Health. 


\section{INTRODUÇÃO}

A fluoretação da água na rede de consumo doméstico é um método utilizado em muitos países do mundo para reduzir a prevalência de cárie dentária, uma estratégia que consegue atingir, praticamente, toda a população e garantir dentes decíduos e permanentes menos expostos a doença.

A ingesta de água fluoretada, a utilização de pasta dental acrescida de flúor, a ingesta de alimentos que utilizam água fluoretada durante seu processamento, entre outras opções de consumo do flúor, são indicadas e devem ser adotadas para que os indivíduos recebam a quantidade da forma iônica do flúor, garantindo dentes saudáveis. (HILAIRIE. 2016).

A Environental Protection Agency (EPA) é a agência de proteção ambiental dos Estados Unidos da América (EUA), a agência tem avaliado estudos ao longo dos anos sobre a adição do flúor a água potável pública consumida pela população. A agência propõe a adição de 4 miligramas por litro (mg/l) de flúor na água potável, medida questionada nos EUA e proibida em vários países europeus. O questionamento é feito a partir dos efeitos danosos do flúor ao corpo humano, como fraturas em crianças e dores articulares em adultos. (SOARES, 2016).

Os EUA utilizam a fluoretação da água comunitária há 75 anos, com resultados que apresentam segurança e benefícios para toda a população. Os dentes dos indivíduos vêm se mantendo saudáveis e fortes, com redução de $25 \%$ de cáries em crianças e adultos. O país e o sistema de saúde economizam, anualmente, com tratamento dentário, utilizando um método prático, eficiente e econômico como a fluoretação da água. (CDC, 2020).

O Centers for Disease Control and Prevention (CDC) acredita que a maior parte da água consumida pela população contém algum percentual de flúor, mas ainda não é o suficiente para eliminar a doença da cárie. As instituições American Dental Association American Academy of Pediatrics, US Public Health Service e Wordl Health Organization confirmam e estimulam a fluoretação da água comunitária. (CDC, 2020).

O flúor é um elemento químico da família dos halogênicos, facilmente encontrado na crosta terrestre, solo, oceanos, água e alimentos (feijão, arroz, gema do ovo, chá preto, espinafre, entre outros). A estimativa diária ideal de ingesta de flúor é em torno de $1,5 \mathrm{mg}$ a $4 \mathrm{mg}$. (SOARES, 2016).

O flúor é absorvido pelo esmalte do dente mesmo antes de nascer, sendo capaz de reparar o esmalte dentário, com a combinação do flúor com outro elemento químico, o fósforo. Alimentos como as carnes, leite e derivados, ovos, grãos, oleaginosas são boas fontes de fósforo. (SOARES, 2016). Curiosamente os refrigerantes a base de cola e as cervejas são produtos com alto teor de fósforo. (SBN, 2021).

Os pesquisadores vêm estudando, outras maneiras de introduzir o flúor na dieta da população, assim o sal tem correspondido a uma destas opções para ser enriquecido com a fluoretação.

Sal é o nome genérico para um grupo de substâncias com características químicas comuns. De todos 
os sais, o mais importante para o ser humano é o cloreto de sódio $(\mathrm{NaCl})$ ou "sal de cozinha" ou "sal comum", seu emprego é universal, consumido tanto em uso doméstico no preparo de alimentos, como também na indústria alimentícia. (SILVA et al., 2020).

Essa característica de universalidade, associado ao fato de ser ingerido regularmente e em pequenas quantidades, o recomendado pela Organização Mundial de Saúde (OMS) é 2,00 g de sódio/dia, torna o sal um veículo ideal para inserir elementos essenciais para o ser humano. Em quase todos os países o sal é adotado para adição de iodo, em outros é usado para veicular também, o flúor. (SILVA et al., 2020; REIS et al., 2021).

A fluoretação da água de abastecimento tem sido o método recomendado pela OMS, tornando-o uma medida de saúde pública de âmbito mundial. O número de estudos científicos envolvendo o sal fluoretado é muito menor quando comparado aos estudos sobre o uso da água fluoretada. Evidências conclusivas têm sido disponibilizadas por países que adotam esse método de fluoretação, identificado o sal fluoretado como tendo um forte efeito tópico na cavidade bucal. (DALL'ONDER, 2016; RIBEIRO, 2018).

Assim, a pergunta de pesquisa é: De que maneira a fluoretação do sal consumido pelo homem pode ajudar na sua saúde bucal?

Este fato traz alguma dificuldade na avaliação da contribuição do sal na prevenção de cáries dentárias.

Dessa forma, este estudo tem como objetivo identificar como a fluoretação do sal para o consumo humano, pode contribuir na saúde da cavidade bucal. Trata-se de um estudo qualitativo, exploratório, de revisão bibliográfica sistemática.

$\mathrm{Na}$ abordagem qualitativa o pesquisador pretende estudar os fenômenos e suas relações com os seres humanos, indo a campo para captar as perspectivas dos envolvidos. Todos os dados coletados são importantes, merecendo receber tratamento para enfatizar os pontos de vista relevantes. (GODOY, 1995).

$\mathrm{Na}$ pesquisa exploratória o pesquisador busca conhecer a variável de estudo, seu significado e o contexto onde ela se encontra. Permite, portanto, conhecer a variável e seus significados na realidade onde se insere. (PIOVESAN; TEMPORINI, 1995).

Utilizou-se busca na Biblioteca Virtual em Saúde (BVS) Odontologia e no Google Acadêmico, por artigos publicados em português, disponibilizados gratuitamente na integra nas bases de dados, a partir das palavras-chaves: Fluoretação do Sal; Sal; Saúde Coletiva.

Outros materiais encontrados, que não correspondiam aos critérios de inclusão do estudo foram excluídos. 


\section{DESENVOLVIMENTO}

A cárie dentária acompanha o homem desde os tempos antigos e medievais, variando sua presença conforme a evolução da espécie humana. Com a utilização e incorporação do açúcar refinado a dieta do homem partir do século XIX, formou-se um verdadeiro exercito de adultos jovens desdentados, já que não havia tratamento ou prevenção para a doença da cárie. (MARTHALER, 2002).

No século XX, a mudança começa acontecer na década de 40, com a fluoretação da água potável pública consumida pela população para a prevenção da cárie. Desde a década de 50, a Pan American Health Organization (PAHO) acompanha a fluoretação do sal de cozinha, outra ação adotada por muitos países na prevenção das cáries dentais.

\subsection{FLÚORETAÇÃO DO SAL NO MUNDO}

Na década de 20, o ginecologista e obstetra suíço Dr. Hans Jacob Wespi recomenda as pacientes gestantes o uso do sal iodado para a prevenção do bócio. Em 1946, o Dr. Hans Jacob Wespi, então Diretor da Clínica de Ginecologia e Obstetrícia do Hospital Cantonal de Aarau na Suíça, adiciona fluoretos ao sal iodado, em uma concentração de $90 \mathrm{mg} / \mathrm{kg}$, e distribui as pacientes gestantes. O médico acreditava que o flúor solúvel acrescido ao sal de cozinha pode ser eficaz na prevenção das cáries dentárias. (MARTHALER, 2002; FRANCO et al., 2003).

Em 1956, o sal fluoretado começa a ser comercializado em Zurique na Suíça, expandido sua venda para outros cantões suíços. (CORDEIRO et al. 2001; MARTHALER, 2013).

Não havia na época evidências científicas que comprovassem o sucesso das ações preventivas, mas os médicos tinham absoluta certeza dos benefícios do sal iodado e da adição de flúor ao sal. (MARTHALER, 2013). O reconhecimento da importância do sal fluoretado na saúde bucal acontece somente na década de 70, com estudos que comprovam a inibição das cáries dentárias. (CORDEIRO et al. 2001).

A primeira experiência industrial, aconteceu na Finlândia em 1953, de enriquecer com 90 mg/kg de fluoreto de potássio ao sal de cozinha. A rotina de consumo do sal de cozinha fluoretado pelos finlandeses, aumentou a partir da década de 70. Entretanto, a partir de 1978 o país suspendeu seu uso, já que a doença da cárie dentária está controlada. (PAHO, 2005).

Outros países europeus adotam a estratégia da fluoretação do sal de cozinha, na proporção de 90 $\mathrm{mg} / \mathrm{kg}$, para a prevenção das cáries dentárias, importando o produto de outros países. A Espanha (1966,1983), a França (1986), a Alemanha (1991), Áustria (1982) e a Hungria (1966). Nas Américas, a Costa Rica (1987), a Jamaica (1987), o México (1988), o Uruguai (1991), Peru (1990), Equador (1998), Cuba (2004) e a Colômbia (1965). (MARTHALER, 2002; DITTERICH et al., 2005; PAHO, 2005).

Segundo Gil et al. (1989 apud Ditterich et al., 2005, p. 232), “[...] para que o sal fluoretado tenha a 
mesma efetividade da água fluoretada $(0,8 \mathrm{ppm})$ a dosagem deveria ser de $250 \mathrm{mgF} / \mathrm{k}$ ". A concentração de flúor, recomendada pela Organização Pan-americana de Saúde Oral, no sal para consumo humano é de 200$250 \mathrm{mgF} / \mathrm{kg}$.

Segundo Franco et al. (2003), na Colômbia, o primeiro programa de fluoretação da água acontece em 1953 na cidade de Girardot, sendo adotado posteriormente nas cidades de Manizales, Cali e Bogotá. O programa de alto custo alcançou uma cobertura de apenas $40 \%$ da população, o que levou o governo colombiano a optar pelo método de fluoretação do sal de cozinha. Foi, então, realizado um cálculo da média de ingestão diária de sal por pessoa em 230 famílias em quatro comunidades. Os resultados avaliados, sobre o consumo de sal, variou entre 3 e 30 gramas diárias por pessoa. Os autores concluem que, para obter o efeito preventivo sobre a cárie dentária, seria necessário agregar $200 \mathrm{mg}$ de fluoreto de potássio em cada $\mathrm{kg}$ de sal (200 ppm). (FRANCO et al., 2003).

Em 1989, o Ministério da Saúde Colombiano aprova o Decreto n ${ }^{\circ} 2024$, ordenando a adição de 180$220 \mathrm{mgF} / \mathrm{kg}$ do produto em cada quilo de sal para consumo humano no país. (FRANCO et al., 2003).

Com a decisão de adotar o sal para fluoretação, surge à necessidade de monitorar permanentemente o cumprimento do decreto. Em 1996, o órgão governamental responsável pela Vigilância de Medicamentos y Alimentos (INVIMA), após pesquisa com amostras de sal de marcas consumidas na Colômbia, reporta que apenas 43,6 \% cumpriam a legislação, 51,9 \% estavam abaixo da norma, ou seja, menos de 180 ppm e 4,5 \% acima de 220 ppm. Em 2000, nova pesquisa mostra que em 34,3\% das amostras havia concentração maior que 220 ppm e $21 \%$ menor que 180 ppm. (FRANCO et al., 2003).

Em 2000, na Colômbia, a INVIMA e o Instituto Colombiano de Bienestar Familiar (ICBF) realizam um novo estudo sobre a concentração do fluoreto de potássio no sal de cozinha, os órgãos encontram concentrações muito variáveis, sugerindo deficiências nos sistemas de adição e no controle de qualidade dos produtos por parte dos produtores e dos organismos de vigilância e controle, ou alterações no produto durante a cadeia de comercialização. (FRANCO et al., 2003).

Em estudo realizado no México, 15 marcas comerciais de sal foram avaliadas, em 75 amostras verificadas quanto à concentração média de fluoreto de potássio no sal de cozinha. Os resultados apontam uma média do valor acrescido entre $266 \pm 67 \mathrm{ppmF}$, variando de 55-355 ppmF na maioria das marcas analisadas. (DITTERICH et al., 2005).

A França, a Alemanha e a Suíça utilizam o sal doméstico com acréscimo do fluoreto de potássio em $250 \mathrm{mgF} / \mathrm{kg}$. A Hungria, demonstra por meio de estudos comparativos, uma variação da presença do produto no sal de cozinha em torno de $350 \mathrm{mgF} / \mathrm{kg}$ e $250 \mathrm{mgF} / \mathrm{kg}$. Os estudos realizados na Hungria destacam que a concentração de $350 \mathrm{mgF} / \mathrm{kg}$, vem apresentando melhor resultado na prevenção da cárie dental. (MACPHERSON; STEPHEN, 2001). Desde 1987, a Jamaica vem acrescentando $250 \mathrm{mgF} / \mathrm{k}$ ao sal para consumo humano. (JONES et al., 2005). 
Os pesquisadores Splieth e Flessa (2008), do Departamento de Prevenção e Dentística Pediátrica da Universidade de Greifswald na Alemanha, em um estudo comparativo analisando a efetividade e custo entre os diferentes métodos de fluoretação empregados no país, constatam que o uso de cremes dentais fluoretados reduz em 20\% a cárie dentária a um custo de US\$2,99 per capita/ano. Quanto ao uso do sal fluoretado na Alemanha, Splieth e Flessa (2008) concluem a redução de 50\% da carie dentária a um custo de US\$ 0,01 per capita/ano. Quando associados, os dois métodos a redução foi de $60 \%$ no índice de cárie, a um preço de US\$3,00 per capita/ano.

A fluoretação da água potável ou do sal, conforme analisado por Splieth e Flessa (2008), comprova a eficácia da ação na saúde pública bucal, dentro de uma política social que visa promover o bem-estar das pessoas. A eficácia tem sido observada por décadas em vários países, através de acompanhamento e estudos científicos que corroboram com esse resultado.

A OMS recomenda o consumo por dia de no máximo 5g (uma colher de chá rasa) de sal por pessoa, equivalendo a 2g de sódio. (PAHO, 2021). Os países europeus conseguem adicionar uma concentração maior de flúor ao sal de cozinha sem causar problemas sérios relacionados à toxicidade. De modo geral, os europeus consomem menos sal do que os latinos americanos. Por exemplo, na Costa Rica o consumo diário de sal por pessoa é de 10 gramas, o mesmo valor de consumo diário de outros países latinos. (DITTERICH et al., 2005).

Para Adam et al. (2005), a fluoretação do sal de cozinha implantado na França em 1980, continua sendo apresentado como a principal ação dentro do programa Frances de saúde dental. Ao completar 10 anos do programa, uma pesquisa realizada em 1991, avaliou a saúde bucal de crianças francesas com a idade de 6 anos. Os resultados mostram um aumento significante (de 61,1\% para 77,8\%) no número de crianças na faixa etária sem experiência de cárie dentária. A França vem investindo em outras medidas como educação, em saúde dental, aumento do uso de cremes dentais fluoretados, utilização do sal fluoretado e ações para melhora no nível de higiene oral da população.

À luz da preleção de Marthaler (2002), estudos realizados na Colômbia e Hungria concluem que em crianças o efeito cariostático do sal fluoretado, quando adotado de forma apropriada, é equivalente à água fluoretada. Na Jamaica, os resultados do índice CPO-D em crianças de 12 anos após a adoção da fluoretação do sal de cozinha, caiu de 6,7 em 1984 para 1,1 em 1995, e em crianças de 15 anos de 9,6 para 3,0 no mesmo período. Na Costa Rica ocorreu uma redução do índice CPO-D em crianças de 12 anos de 8,4 em 1988, para 4,9 em 1992. No México, o índice encontrado foi 4,39 em 1988, para 2,47 em 1997, correspondendo a uma redução de $44 \%$.

O acrescimento do fluoreto de potássio ao sal de cozinha apresenta ótimos resultados para a eliminação da cárie dentária, produzindo uma migração dos cirurgiões-dentistas para a odontologia estética.

Entretanto, a cárie dentária continua sendo um problema nas camadas socioeconômicas mais baixas 
nos países em desenvolvimento, inclusive nos países ricos. A situação exige um novo posicionamento do atendimento odontológico em todos os países, pois a cárie é uma doença socialmente injusta. (MARTHALER, 2002; ADAM et al., 2005).

\subsection{FLUORETAÇÃO DO SAL NO BRASIL}

No Brasil, as normas e documentos que servem de referência para o sal destinado ao consumo humano são principalmente o Decreto $\mathrm{n}^{0}$ 75.697, de 6 de maio de 1975, que estabelece os padrões de identidade e qualidade para o produto. (BRASIL, 1975). A Resolução RDC nº 130, de 26 de maio de 2003, situa o teor de iodo no sal. (ANVISA, 2003).

Os documentos referem-se aos aspectos do sal para consumo humano e a adição de iodo, sem que haja qualquer referência a fluoretação do sal no país. A necessidade de controle da produção industrial do sal para consumo humano, quando agregado algum agente químico como o iodo e/ou flúor é necessário para prevenir irregularidades na dosagem desses elementos.

No Brasil, a adição do iodato de potássio ao sal começou na década de 1950, como uma ação preventiva as doenças provenientes da deficiência do iodo. Em 2013, a Agência Nacional de Vigilância Sanitária (ANVISA) estipulou a quantidade do produto em 15 e 45 miligramas adicionados por quilo de sal. (BRASIL, 2013).

O iodo regula o crescimento e desenvolvimento humano. A insuficiência do micronutriente no organismo pode gerar o aparecimento de uma doença denominada "bócio", causando no ser humano adulto fadiga e apatia, e nas crianças problemas relacionados ao crescimento e a redução da capacidade de concentração e aprendizagem. (SILVA; MELCHERT, 2019).

No Brasil, o órgão responsável pelo controle da dosagem de iodo no sal para consumo humano é o Instituto de Metrologia, Normalização e Qualidade Industrial (INMETRO).

Em 1958, a Organização Mundial da Saúde (OMS) reconheceu a fluoretação da água como uma importante estratégia da saúde pública para a prevenção da cárie. A organização incentiva os países membros a promover a estratégia em seus territórios, a partir de um programa de fomentação criado em 1975. (ROSSI et al., 2020).

Em 1974, o governo federal brasileiro sanciona a Lei $\mathrm{n}^{\circ} 6.050 / 74$ que regulamenta o Decreto $\mathrm{n}^{\circ}$ 76.872/75, liberando financiamentos e créditos para os estados implantarem a fluoretação da água em sistemas de abastecimento público. (ROSSI et al., 2020).

Em 1977, a Fundação de Serviço Especial de Saúde Pública (FSESP) começou a realizar pesquisas sobre a fluoretação do sal de cozinha no Brasil. Os pesquisadores tinham como perspectiva atingir toda a população com o sal fluoretado, erradicando as cáries dentárias em todas as camadas sociais da população. A instituição contou com o apoio do governo federal, salineiras e sanitaristas envolvidos com a saúde bucal. 
(CORDEIRO et al. 2001).

As conclusões do estudo foram promissoras, apontando a eficácia do uso do flúor e absorção pelo corpo humano, quando oferecido tanto na água potável como no sal de cozinha. Entretanto, justificou que o uso do sal fluoretado deve ser utilizado em regiões onde haja falta de acesso a água potável pública e com controle técnico permanente. A fórmula de oferecimento do flúor no Brasil continua sendo a tradicionalmente utilizada há décadas, a fluoretaçao da água pública, entrega de dentríficios com flúor aos escolares e os bochechos fluorados nas escolas - utilizado para atingir as crianças de áreas rurais e de áreas sem água tratada. (CORDEIRO et al. 2001).

Membros da classe acadêmica brasileira, como professores e pesquisadores de universidades federais apoiaram a fluoretração do sal de cozinha. Em 1989, a Fundação W. K. Kellog apoia a criação da Fundação Cedros, entre suas metas, fundação estabeleceu sete grupos de trabalho, entre eles: fluoretação do sal; fluoretação das águas e saúde bucal nos Sistemas Locais de Saúde (SILOS). (CHIANCA, 1992; ROSSI, 2018).

A fluoretação do sal de cozinha chegou a ser abordada na mídia brasileira na década de 1990, a proposta apresentada foi a fluoretação do sal de cozinha para a prevenção da cárie dentária em regiões do Brasil onde não existem estações de tratamento de água pública. (ROSSI, 2018).

Em 1990, o Ministro da Saúde Alceni Guerra assinou a Portaria n ${ }^{\circ}$ 1.437, de 14 de dezembro de 1990, criando o "Programa Nacional de Controle da Cárie Dentária”. Em 1991, através da Portaria n 1, de 6 de fevereiro de 1991, assinada pelo presidente do Instituto Nacional de Alimentação e Nutrição (INAN) Marcos de Carvalho Candau e pelo diretor da Divisão Nacional de Saúde Bucal (DNSB) Sérgio de Carvalho Weyne foi criada a Coordenadoria Geral do Programa Nacional de Controle da Cárie Dentária que apoiava o método de adição de fluoretos de potássio ao sal de cozinha. (ROSSI, 2018).

Em 1992, a empresa salineira Perynas chegou a desenvolver o sal fluorado refinado e iodado Biosal e o sal fluorado refinado extra iodado MOC. Os moradores do município de Cabo Frio, no estado do Rio de Janeiro, foram os primeiros a consumir o sal fluoretado produzido pela salineira Perynas. (ROSSI, 2018).

Em 1993, ocorreu a suspensão do programa de fluoretação do sal de cozinha, gerando ao Ministério da Saúde explicações sobre a medida tomada. Entre 1994 e 1997, vários projetos foram conduzidos ao Congresso Nacional tentando a obrigatoriedade da fluoretação do sal de cozinha, entretanto todos os documentos foram arquivados. (ROSSI et al., 2020).

A suspensão "definitiva" do sal de cozinha fluoretado no Brasil foi apoiada por sanitaristas e entidades como o Movimento Brasileiro de Renovação Odontológica (MBRO), participantes do Encontro Nacional de Administradores e Técnicos do Serviço Público Odontológico (ENATESPO) e membros da Associação Brasileira de Odontologia de Promoção de Saúde (ABOPREV), além de cirurgiões-dentistas contrários a qualquer método de fluoretação. (ROSSI et al., 2020). 
No ano 2000, o movimento antiflúor consegue enviar matérias legislativas solicitando a suspensão da fluoretação de todo e qualquer produto de consumo humano (água, dentríficios, entre outras) no território nacional. O Conselho Federal de Odontologia (CFO) consegue se posicionar fortemente contra esta ação, fortalecendo a saúde pública bucal brasileira e enaltecendo o papel da fluoretação na prevenção da cárie dentária. (ROSSI et al., 2020).

\section{A pesquisa Cobertura e Vigilância da Fluoretação da Água de Abastecimento Público no}

Brasil, 2010-2015, ou Projeto Vigifluor, apresentou em 2017, os resultados do período quanto à fluoretação de água em municípios com mais de 50 mil habitantes localizados os vinte e sete unidades da Federação. As informações obtidas no estudo apresentam um panorama de desigualdades e grau de iniquidades no cumprimento da Lei Federal para fluoretação da água potável pública. (NARVAI; FRAZÃO, 2017).

Aproximadamente, 96,5(68,3\%) milhões de pessoas, residentes em municípios com mais de 50 mil pessoas, tem acesso à água potável fluoretada. A Região Sul tem a melhor cobertura com 88,7\% e a Região Norte possui a menor cobertura com 25,3\%. (NARVAI; FRAZÃO, 2017).

Quando analisada a cobertura por estado e extremidades do território nacional, os estados da Paraíba (leste), Acre (oeste) e Amapá (norte) não acrescenta fluoretos à água pública, infligindo a legislação federal sobre o tema. O estado do Rio Grande do Sul atende $89 \%$ da sua população, beneficiando e oferecendo água potável fluoretada praticamente em quase todo estado. (NARVAI; FRAZÃO, 2017).

A vigilância da qualidade da água com fluoreto para consumo humano, também foi avaliado, os resultados apontam as regiões Sul e Sudeste com os melhores serviços de vigilância de qualidade e péssimos serviços de vigilância nas demais regiões. (NARVAI; FRAZÃO, 2017).

Os pesquisadores sugerem uma segunda etapa de estudo, para a avaliação da fluoretação da água pública distribuída nos municípios com menos de 50 mil habitantes.

Os estudos de Jones et al. (2005); Splieth e Flessa (2008), comprovam que a fluoretação da água comunitária ou a adição de fluoretos ao sal de cozinha, apontam similaridade de resultados quanto a eficácia da ação na prevenção da cárie dentária. Os pesquisadores apontam a necessidade de uma concentração adequada do flúor, que evite a hipofluoretação ou a hiperfluoretação na água e/ou no sal. A escolha do método vai depender do melhor custo-benefício para a população, porém apontam um custo insignificante e alto contingente populacional atingido pela fluoretação do sal de cozinha.

Do ponto de vista da segurança, ambos os métodos, quando utilizados nas concentrações recomendadas, não apresentam riscos à saúde. 


\section{CONSIDERAÇÕES FINAIS}

O uso do fluoreto de potássio na prevenção da cárie dentária tem sido estudado e utilizado a partir da metade do século XX. Informalmente, o médico H. J. Wespi fornecia as gestantes que atendia em seu consultório sal enriquecido com iodo e flúor para ser adicionada a comida, buscando a prevenção do bócio e das cáries dentárias.

Em 1958, a Organização Mundial da Saúde (OMS) reconheceu a fluoretação como estratégia para a prevenção da cárie. Muitos países da Europa e da América Latina utilizam a adição de fluoretos ao sal, alcançando ótimos resultados na prevenção da cárie.

Na década de 1970, o Brasil estabeleceu a legislação para o enriquecimento da água potável pública com flúor. Várias tentativas para implantação definitiva de um programa oficial de fluoretação do sal de cozinha foram realizadas, entretanto há décadas o país optou pela fluoretação da água pública.

Os resultados do estudo Vigifluor realizado entre 2010-2015 e publicado em 2017, destacou as desigualdades de acesso da população a água fluoretada pública.

Um estado de exclusão do acesso aos direitos sociais básicos, como por exemplo, o emprego, renda salarial digna, moradia, saúde, educação adequada, saneamento básico, repercute sobre a população em uma qualidade de vida ruim. Dessa forma, má qualidade de vida produz sobre a saúde bucal um resultado totalmente negativo. Uma saúde bucal ruim, portanto, representa um claro sinal de uma condição de vida precária, como também, de exclusão social.

Os resultados do nosso estudo apontam a necessidade de planejamento de um plano operativo para fortalecer a prevenção na saúde bucal, com a utilização da água potável fluoretada pública de qualidade a ser oferecida para a população, investigação da fonte de fluoretos oferecidos pelo poder público nos municípios com menos de 50mil habitantes e a proposição de outras formas de oferecimento do flúor a população em situação de vulnerabilidade em relação a saúde bucal. 


\section{REFERÊNCIAS}

ADAM, C.; EID, A.; RIORDAM, P.J.; WOLIKOW, M.; COHEN, F. Caries experience in the primary dentition among French 6-year-old betwen 1992 and 2000. Communit Dentistry and Oral Epidemiology, v. 33, n. 5, p. 333-340, 2005.

ANVISA. Resolução RDC $\mathbf{n}^{0}$ 130, de 26 de maio de 2003. Brasília: 2003. Disponível em: http://www.anvisa.gov.br/legis/resol/2003/rdc/130_03rdc.htm\#. Acesso em: 11 ago. 2021.

BRASIL. ANVISA reduz quantidade de iodo no sal de cozinha. Canalsaude.fiocruz.br, Rio de Janeiro, 2013. Disponível em: https://www.canalsaude.fiocruz.br/noticias/noticiaAberta/anvisa-determinareducao-do-teor-de-iodo-no-sal-2013-04-

17\#: :text=A\%20nova\%20medida\%20entra\%20em,e\%2060\%20mg\%20de\%20iodo. Acesso em: 11 out. 2021.

BRASIL. Ministério da Saúde. Decreto no 75.697, de 06 de maio de 1975. Brasília: Ministério da Saúde, 1975. Disponível em: http://www2.camara.gov.br/legin/fed/decret/1970-1979/decreto-75697-6-maio1975-424211-publicacaooriginal-1-pe.html. Acesso em: 11 ago. 2011.

CDC. Community water fluoridation. CDC, Washington, 2020. Disponível em: https://www.cdc.gov/fluoridation/index.html?CDC_AA_refVal=https\%3A\%2F\%2Fwww.cdc.gov\%2Fflu oridation\%2Findex.htm. Acesso em: 16 set. 2021.

CHIANCA, T. K. (coord.). O que fazer nos municípios? GT saúde bucal em SILOS: Rede CEDROS, 1992. Rio de Janeiro: Cedros, 1992. (Cadernos de Saúde Bucal 1).

CORDEIRO, Eudes Davi; FRANÇA, Hélio Marques; FONSECA, Thales Vilas Boas; MENDES, Júlio Cesar; HONDA Daniela. Cinquentenário da programação científica da odontologia pública brasileira: ascensão e esgotamento do paradigma Sespiano. 2001. Monografia (Especialista em Odontologia em Saúde Coletiva) - Departamento de Ciências da Saúde, Universidade de Brasília, Brasília, 2001. Disponível em: https://bdm.unb.br/bitstream/10483/1137/1/2001_EudesDaviCordeiro.pdf. Acesso em: 16 set. 2021.

DALL'ONDER, Ana Paula. Sal fluoretado na prevenção da cárie dentária. 2016. Trabalho de Conclusão de Curso (Graduação em Odontologia) - Faculdade de Odontologia, Universidade Federal do Rio Grande do Sul, Porto Alegre, 2016. Disponível em: https://www.lume.ufrgs.br/bitstream/handle/10183/200276/001017206.pdf?sequence=1\&isAllowed=y. Acesso em: 16 set. 2021.

DITTERICH, R. G.; RODRIGUES, C. K.; WAMBIER, D. S. O sal fluoretado como alternativa em saúde bucal coletiva: vantagens e desvantagens. Revista do Instituto de Ciências da Saúde, v. 23, n. 3, p. 231234, 2005.

FRANCO, A. M.; SALDARRIAGA, A.; GONZALEZ, M. C.; MARTIGNON, S.; ARBELÁEZ, M. I.; OCAMPO, A.; MOONLIGHT, M. Concentración de flúor en la sal de cocina en cuatro ciudades colombianas. Revista CES Odontologia, Medelín, v. 16, n. 1, p. 21-26, 2003.

GODOY, A. S. Pesquisa qualitativa: tipos fundamentais. Revista de administração de Empresas, v. 35 , n. $3,20-29, \quad$ p. $1995 . \quad$ Disponível https://www.scielo.br/j/rae/a/ZX4cTGrqYfVhr7LvVyDBgdb/?format=pdf\&lang=pt. Acesso em: 30 ago. 2021. 
HILARIE, M. S. To fluoridate or not to fluoridate. Watertechonline.com, Califórnia, 2016. Disponível em: https://www.watertechonline.com/wastewater/article/15549906/to-fluoridate-or-not-to-fluoridate. Acesso em: 16 set. 2021.

JONES, S.; BURT, B. A.; PETERSEN, P. E.; LENNON, M. A. The effective use of fluorides in public health. Bulletin of the World Health Organization, v. 83, n. 9, p. 670-676, 2005.

MACPHERSON, L. M. D.; STEPHEN, K. W. The effect on human salivary fluoride concentration of consuming fluoridated salt-containing baked food items. Archives of Oral Biology, v. 46, n. 10, p. 983 988, 2001.

MARTHALER, T. M. Dentistry between pathology and cosmetics. Community Dentistry and Oral Epidemiology, v. 30, n. 1, p. 3-15, 2002.

MARTHALER, T. M. Salt fluoridation and oral health. Acta medica Academia, v. 42, n. 2, p. 140-155, 2013. Disponível em: http://ama.ba/index.php/ama/article/viewFile/185/pdf_18. Acesso em: 16 set. 2021.

NARVAI, P. C.; FRAZÃO, P. Brasil: as marcas da desigualdade também na cobertura da fluoretação e na vigilância da água. In: NARVAI, P. C.; FRAZÃO, P. (org.). Cobertura e vigilância da fluoretação da água no Brasil: municípios com mais de 50 mil habitantes. São Paulo: Faculdade de Saúde Pública da USP, 2017. p. 186-199.

PAHO. Promoting oral health: the use of salt fluoridation to prevent dental caries. Washington: PAHO, 2005.

PAHO. Novos parâmetros de referência da OMS ajudam países a reduzir ingestão de sal e salvar vidas. Paho.org, Brasília, 2021. Disponível em: https://www.paho.org/pt/noticias/5-5-2021-novos-parametrosreferencia-da-oms-ajudam-paises-reduzir-ingestao-sal-e-salvar. Acesso em: 16 set. 2021.

PIOVESAN, A.; TEMPORINI, E. R. Pesquisa exploratória: procedimento metodológico para o estudo de fatores humanos no campo da saúde pública. Rev Saúde Pública, v. 29, v. 4, p. 318-325, 1995. Disponível em: https://www.scielo.br/j/rsp/a/fF44L9rmXt8PVYLNvphJgTd/?format=pdf\&lang=pt. Acesso em: 16 set. 2021.

REIS, L. C. M.; SILVA, F. L.; MONTEIRO, A. L.; SOUSA, M. A. A.; LOBÃO, A. G. S. R.; CERQUEIRA, R. G. M.; CARNEIRO, S. C. P.; CASTRO, S. A. D. A influência do zinco, selênio e iodo na suplementação dietética em pessoas com hipotireoidismo. Pesquisa, Sociedade e Desenvolvimento, v. 10, n. 16, p. e268101623719, 2021. Disponível em: https://rsdjournal.org/index.php/rsd/article/view/23719. Acesso em: 13 dez. 2021.

RIBEIRO, ANNA CARLA. Avaliação da capacidade de remoção de fluoretos da água através da absorção em mica. 2018. Dissertação (Mestrado em Engenharia do Ambiente) - Instituto Superior de Agronomia, Universidade de Lisboa, Lisboa, 2018. Disponível em: https://www.repository.utl.pt/handle/10400.5/15869. Acesso em: 16 set. 2021.

ROSSI, T. R. A. Fluoretação do sal de cozinha e movimento anti-flúor. In: Rossi, T. R. A. (org.). Produção social das políticas de saúde bucal no Brasil [online]. Salvador: EDUFBA, 2018. p. 123-154. Disponível em: https://books.scielo.org/id/mpgzk/pdf/rossi-9788523220228-07.pdf.

Acesso em: 16 set. 2021. 
ROSSI, T. R. A.; MOREIRA, L. G. P.; BARROS, S. G. Decurso histórico das políticas de fluoretação como estratégia de enfrentamento à cárie dentária no poder legislativo brasileiro, de 1963 a 2019. Cad. Saúde Pública, v. 36, n. 4, e00208418, 2020. Disponível em: https://www.scielosp.org/pdf/csp/2020.v36n4/e00208418/pt. Acesso em: 11 ago. 2011.

SOCIEDADE BRASILEIRA DE NEFROLOGIA - SBN. Pacientes em tratamento conservador. Sbn.org.br, São Paulo, 2021. Disponível em: https://www.sbn.org.br/orientacoes-etratamentos/orientacoes-nutricionais/. Acesso em: 16 set. 2021.

SILVA, A. R. M.; MELCHERT, W. R. Iodo: riscos e benefícios para a saúde humana. Cienc. Cult., v. 71, n. 2, p. 58-60, 2019. Disponível em: http://cienciaecultura.bvs.br/pdf/cic/v71n2/v71n2a16.pdf. Acesso em: 11 ago. 2011.

SILVA, A. L. S.; MARTINS, D. G.; MOURA, P R. G.; GARCIA, A. R. S. M. Um referencial teórico acerca do íon do sódio e seu sal principal ocorrência cotidiana - o cloreto de sódio - potencialmente contributivo ao ensino de química. Revista DI@LOGUS, v. 9, n. 2, p. 41-6, 2020. Disponível em: https://revistaeletronica.unicruz.edu.br/index.php/dialogus/article/view/52/204. Acesso em: 16 set. 2021.

SOARES, F. P. Flúor: Algumas curiosidades e verdades que você precisa saber. Dentate.com.br, São Paulo, 2016. Disponível em: https://www.dentate.com.br/post/2016/07/25/f1\%C3\%BAor-algumascuriosidades-e-verdades-que-voc\%C3\%AA-precisa-saber. Acesso em: 16 set. 2021.

SPLIETH, C. H.; FLESSA, S. Modelling lifelong costs of caries with and without fluoride use. European Journal of Oral Sciences, v. 116, p. 164-169, 2008. 